\title{
Estimation of Calibration Uncertainties in the Detector-Based Photometric Calibrations
}

\author{
F. SAMETOGLU* \\ TÜBİTAK-Ulusal Metroloji Enstitüsü (UME) \\ Gebze, 41470, Kocaeli, Turkey \\ (Received May 19, 2008)
}

\begin{abstract}
Uncertainty evaluations in the photometric calibrations and established uncertainty budgets at National Metrology Institute of Turkey (TUBITAK-UME) are presented. Uncertainty analyses are cover calibrations of the luminous intensity, the luminous flux and the luminance properties of the optical light source. The combined uncertainty in each photometric calibration was evaluated using developed uncertainty models. The degrees of freedom in each input and output quantities were also determined. The coefficient of uncertainty contribution $h\left(y, x_{i}\right)$ was finally determined to present the dominant and less important contributions.
\end{abstract}

PACS numbers: 06.20.-f, 06.20.Dk, 06.20.fb, 07.60.Dq

\section{Introduction}

In metrology, a value assigned to a physical quantity refers to the related SI unit and it is distributed as characterized by the associated measurement uncertainty. The concept of measurement uncertainty was internationally agreed and its determination was explained by some general rules. The related terms are collected in the Guide to the Expression of Uncertainty in Measurement (GUM) [1]. The Guide has been universally adopted in the national metrology institutes and its use is propagating through to calibration laboratories providing traceable measurements. Using the ISO-GUM as the basis, the European Cooperation for Accreditation has also published the document Expression of the Uncertainty of Measurement in Calibration, referred to as EA-4/02 [2].

The knowledge about the measurement process is to be represented by the so-called model equation which establishes the mathematical interrelation between the measurand $Y$ and the input quantities $x_{i}$ through the relationship $Y=f\left(x_{1}, x_{2}, \ldots, x_{N}\right)[1,3]$. So uncertainty in the measurand $Y$ is given by

*e-mail: ferhat.sametoglu@ume.tubitak.gov.tr 


$$
u^{2}(Y)=\sum_{i=1}^{N}\left(\frac{\partial f}{\partial x_{i}}\right)^{2} u^{2}\left(x_{i}\right)+2 \sum_{i=1}^{N-1} \sum_{j=i+1}^{N} \frac{\partial f}{\partial x_{i}} \frac{\partial f}{\partial x_{j}} u\left(x_{i} x_{j}\right),
$$

where $u\left(x_{i}\right)$ is the uncertainty in $x_{i}$ and $u\left(x_{i} x_{j}\right)$ is the covariance of $x_{i}$ and $x_{j}$. The covariance is zero for uncorrelated input quantities and therefore Eq. (1) can be rewritten as

$$
u^{2}(Y)=\sum_{i=1}^{N}\left(\frac{\partial f}{\partial x_{i}}\right)^{2} u^{2}\left(x_{i}\right)=\sum_{i=1}^{N}\left[c_{i} u\left(x_{i}\right)\right]^{2} .
$$

The derivatives $\partial f / \partial x_{i}$ are sensitivity coefficients $\left(c_{i}\right)$ for the dependence of $Y$ on the various measured quantities. When the input variables $x_{1}, x_{2}, \ldots, x_{N}$ are mutually uncorrelated, the GUM uses the product $u_{i}(y)=c_{i} u\left(x_{i}\right)$ as the contribution to the standard uncertainty $u_{\mathrm{c}}(y)$ from $u\left(x_{i}\right)$.

The output quantity is combined from several input quantities and many of these are minor affecting the value of the output quantity. Therefore, no new measurements are carried out for those input quantities. In this case, former results are used and the standard uncertainty for the quantity can be calculated from type $\mathrm{B}$ evaluations using a rectangular, a sinus or a triangular probability distribution functions $(p d f)$. A uniform rectangular $p d f$ is the most probable assumption in an estimation which is equal to $u\left(x_{i}\right)=a / \sqrt{3}$ ( $a$ is the value) [1].

The degree of freedom $v_{i}$ of a standard uncertainty $u\left(x_{i}\right)$ obtained from a type A evaluation is calculated as $v_{i}=n-1$. It is more problematic to associate degree of freedom with a standard uncertainty obtained from a type B evaluation. Therefore the degree of freedom for such uncertainty may be taken to be $v_{i}=$ $\infty$. The effective degree of freedom $v_{\text {eff }}$ of an output quantity $y$ with standard uncertainty $u(y)$ is calculated from the Welch-Satterthwaite formula [1, 2]:

$$
v_{\mathrm{eff}}=\frac{u^{4}(y)}{\sum_{i=1}^{n} \frac{u_{i}^{4}(y)}{v_{i}}} .
$$

This formula is important for estimation the value of a coverage factor $k$.

All of uncertainty components which used in the uncertainty analysis for a measurement (calibration) uncertainty are generally present in the uncertainty budget. The uncertainty budget lists all quantities mentioned in the model and gives a specified amount of information for each entry. The advantage of the budget is that the uncertainty budget enables to detect dominant and less important contributions. The dominant components of the combined uncertainty can also be identified by calculating the coefficient of contribution $h\left(y, x_{i}\right)[4]$ :

$$
h\left(y, x_{i}\right)=\frac{u_{i}^{2}(y)}{u^{2}(y)}=\left[\frac{c_{i} u\left(x_{i}\right)}{u(y)}\right]^{2} .
$$

The coefficients of contribution indicate the degree of contribution for the combined standard uncertainty from their components. At each stage, the contribution of each component to the combined uncertainty is computed. 
In this article, calibration procedures for the luminous intensity, the luminous flux and the luminance performed at UME are presented and the methods of the ISO Guide are used to estimate uncertainties in related calibrations by establishing uncertainty budgets.

\section{Evaluation of the uncertainty in photometric calibrations}

Calibrations of the luminous intensity, the luminous flux and the luminance units and their uncertainty analyses are presented. The luminous intensity and the luminance calibrations were carried out by using the detector-based technique whereas the luminous flux calibration was performed using the working standard lamp (WSL).

\subsection{Uncertainty evaluation in the luminous intensity calibration}

The new traceability chain in photometric measurements has been established at UME by realization of SI-based unit of candela with characterized filter radiometers traceable to UME primary-level cryogenic radiometer with expanded uncertainty of $0.30 \%(k=2)[5]$.

The detector-based luminous intensity calibrations are carried out at UME on a six-meter long optical bench [6]. The optical bench contains: (i) an enclosed cabinet for mounting a lamp under the calibration (LUC), (ii) a rack with a computer for monitoring and to control of electrical parameters of the LUC, (iii) a carriage on rail for gliding the reference photometer (RP) from the LUC up to $6 \mathrm{~m}$ and (iv) a set of baffles between the LUC and the RP for reducing stray light (Fig. 1).

The LUC was placed on an alignment stage (AS1) mounted within a light-tight cabinet. A highly-stable dc power supply (PS) was used to operate the LUC at constant-current mode. The operating current of the LUC was monitored via the voltage drop across a calibrated shunt resistor using a calibrated digital voltmeter (DVM1) and the LUC voltage was monitored by using another DVM2. The RP with known illuminance responsivity was used in calibration, which had a thermostabilized housing containing an aperture, a $V(\lambda)$ correction filter and a $\mathrm{Si}$ photodiode. The generated photocurrent at the output of the RP was measured using a calibrated photocurrent meter (PCM).

Tungsten filament lamp (Osram Wi41/G) was used as the LUC for evaluation of the uncertainty in the luminous intensity calibration. The LUC was operated at color temperature of $\approx 2856 \mathrm{~K}$. The operating current required to obtain $2856 \mathrm{~K}$ had been determined by measuring the spectral irradiance of the lamp using a filter radiometer and a set of band-pass filters [5]. Then the RP was glided to a distance $d(\mathrm{~m})$ from the LUC and the luminous intensity of the LUC $\left(I_{\mathrm{LUC}}\right)$ was calculated from the generated photocurrent $P_{\mathrm{c}}(\mathrm{A})$ and the illuminance responsivity of the $\mathrm{RP}\left(s_{v}, \mathrm{~A} / \mathrm{lx}\right)$ according to the following equation: 


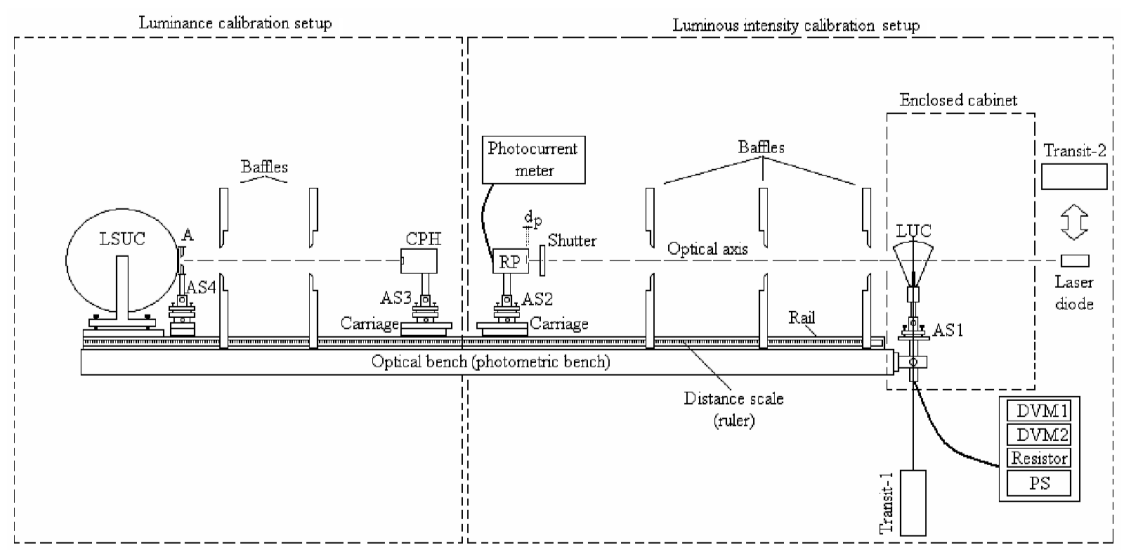

Fig. 1. Optical bench for photometric calibrations of the luminous intensity and the luminance. RP is the reference photometer, LUC is the lamp under the calibration, AS1 to AS4 are alignment stages, DVM1 and DVM2 are digital voltmeters, PS is the power supply, LSUC is the luminance source under the calibration and A is the calibrated aperture.

$$
I_{\mathrm{LUC}}=d^{2} \frac{P_{\mathrm{c}}}{s_{\mathrm{v}}} c c f
$$

where $c c f$ is color-correction factor of the RP.

The developed uncertainty model on the basis of calibration equation for estimating the uncertainty in the luminous intensity calibration of a light source is shown below

$$
\begin{aligned}
I_{\mathrm{LUC}} & =\left[\frac{\left(c_{\mathrm{DVM}}+c_{\mathrm{DVMD}}\right) U_{\mathrm{L}}}{U_{\mathrm{L}}(J) R\left(1+R_{\mathrm{D}}+\alpha_{\mathrm{RS}} \Delta T\right)}\right]^{m_{\mathrm{i}}}\left(d+d_{\mathrm{p}}+\alpha_{\mathrm{RS}} \Delta T\right)^{2} \\
& \times\left[\frac{\left(P_{\mathrm{c}}+c_{\mathrm{PCM}}+c_{\mathrm{PCMD}}\right)}{\left(s_{\mathrm{v}}+s_{\mathrm{VD}}\right)}\right] c c f \text { scf } M_{\mathrm{R}}\left(1-L_{a \epsilon}-L_{a \phi}-P_{a \theta}-P_{\mathrm{N}}\right) .
\end{aligned}
$$

The first parenthesis shows estimated uncertainty sources in the current stability of the LUC. It includes uncertainties in: (i) calibration factor $\left(c_{\mathrm{DVM}}\right)$ of the digital voltmeter (DVM) that was used for measuring the LUC current and its short-term drift $\left(c_{\text {DVMD }}\right)$ between recalibrations, (ii) the voltage drop $\left(U_{\mathrm{L}}\right)$ across the reference shunt resistor $(R)$ that was used for the monitoring of the LUC current, (iii) the operating current of the LUC $\left(U_{\mathrm{L}}(J)\right)$ assigned for color temperature of $2856 \mathrm{~K}$, (iv) the resistance value $(R)$, short-term drift $\left(R_{\mathrm{D}}\right)$ and the temperature coefficient $\left(\alpha_{\mathrm{RS}} \Delta T\right)$ of the reference shunt resistor and (v) exponent for changes of lamp current affecting the luminous intensity $\left(m_{\mathrm{i}}\right)$. The second parenthesis shows estimated uncertainty components in the distance measurement between the LUC and the RP. They are: (i) measured photometric distance $(d)$ between the center plane of the filament of lamp and the outermost surface of the RP, (ii) the offset distance $\left(d_{\mathrm{p}}\right)$ between the outermost surface of the RP and center of its aperture and (iii) thermal expansion coefficient $\left(\alpha_{\mathrm{RS}} \Delta T\right)$ of the 
stainless steel ruler that was mounted on the rail and used for the photometric distance measurement. The third parenthesis shows uncertainty sources in the illuminance measurement of the lamp at the RP surface. It includes uncertainties in: (i) the photocurrent reading $\left(P_{\mathrm{c}}\right)$, (ii) calibration factor $\left(c_{\mathrm{PCM}}\right)$ of the $\mathrm{PCM}$ that was used for measuring the photocurrent and its short-term drift $\left(c_{\mathrm{PCMD}}\right)$ between recalibrations and (iii) the illuminance responsivity $\left(s_{\mathrm{V}}\right)$ and short-term drift $\left(s_{\mathrm{vD}}\right)$ of the RP. The last parenthesis shows other factors (supplementary input quantities) that affect the luminous intensity (output quantity). It includes uncertainties in: (i) vertical $\left(L_{a \epsilon}\right)$ and horizontal $\left(L_{a \phi}\right)$ alignments of the lamp filament, (ii) angular alignment of the RP $\left(P_{a \theta}\right)$, (iii) nonlinearity $\left(P_{\mathrm{N}}\right)$ of the RP. There are also three correction factors in the uncertainty model which are used for color-correction $(c c f)$, stray light correction $(s c f)$ and measurement repeatability $\left(M_{\mathrm{R}}\right)$.

Table I gives established uncertainty budget for the detector-based luminous intensity calibration of an aged $180 \mathrm{~W}$ tungsten filament lamp of type Osram Wi41/G performed at UME.

The lamp current was automatically controlled by a computer feedback system to keep the current variation within $\pm 0.002 \%$. The operating current required to achieve the color temperature of lamp at $2856 \mathrm{~K}$ had been determined as $5.8472 \mathrm{~A} \pm 0.0006 \mathrm{~A}$ (coverage factor $k=1$ ) by repeated measurements of the spectral irradiance of the lamp [5]. The operating current of the LUC was monitored via the voltage drop across a reference shunt resistor (Guildline - $0.1 \Omega$ ) using a HP-3456 model as DVM. The calibration factor of the DVM is $c_{\mathrm{DVM}}=0.999992$ and it had been stated in the certificate given by Voltage Standards Laboratory of UME with relative expanded uncertainty of $0.000008(k=2)$. Thus, the standard uncertainty was calculated as $u\left(c_{\mathrm{DVM}}\right)=(0.999992 \times 0.000008 / 2)=0.000004$. The DVM is recalibrated annually by Voltage Standards Laboratory utilizing the same calibration setup. The drift of the calibration factor of the DVM since its last calibration was estimated from its calibration history to be +0.000001 with standard deviation of $s\left(c_{\text {DVMD }}\right)=0.0000007$. Thus, the standard uncertainty of $u\left(c_{\text {DVMD }}\right)$ was assumed with a rectangular type of distribution $(\mathrm{RTD})$ and estimated as $u\left(c_{\text {DVMD }}\right)=s\left(c_{\text {DVMD }}\right) / \sqrt{3}=0.0000004$.

Precision four-terminal standard dc current shunt operating in air, Guildline Instruments $9230 / 15$, was used to monitor the current of the LUC. The calibrated resistance value of the shunt resistor is $R=0.099994 \Omega$. Resistor had been calibrated with relative expanded uncertainty of $0.000040(k=2)$ by the Impedance Standards Laboratory of UME. Thus, the standard uncertainty in the resistance value was calculated as $u(R)=(0.099994 \times 0.000040 / 2)=0.0000020 \Omega$. The current shunt is recalibrated annually by the Impedance Standards Laboratory and the drift of the resistance value of the shunt since its last calibration was estimated from its calibration history to be -0.0000010 with standard deviation of $s\left(R_{\mathrm{D}}\right)=0.0000007$. Thus, the standard uncertainty of $u\left(R_{\mathrm{D}}\right)$ was assumed with 
TABLE I

Uncertainty budget established at UME for the luminous intensity calibration of an Osram Wi41/G type of optical light source.

\begin{tabular}{|c|c|c|c|c|c|c|}
\hline $\begin{array}{c}\text { Quantity } \\
X_{i}\end{array}$ & $\begin{array}{c}\text { Estimate } \\
x_{i}\end{array}$ & $\begin{array}{c}\text { Standard } \\
\text { uncertainty } \\
u\left(x_{i}\right)\end{array}$ & $\begin{array}{l}\text { Probability } \\
\text { distribution }\end{array}$ & $\begin{array}{c}\text { Sensitivity } \\
\text { coefficient } \\
c_{i}\end{array}$ & $\begin{array}{c}\text { Uncertainty } \\
\text { contribution } \\
u_{i}(y)[\mathrm{cd}]\end{array}$ & $\begin{array}{c}\text { Contribution } \\
\text { coefficient } \\
h\left(y, x_{i}\right)[\%]\end{array}$ \\
\hline$c_{\mathrm{DVM}}$ & 0.999992 & 0.000004 & normal & $1762.65 \mathrm{~cd}$ & 0.00705 & 0.02 \\
\hline$c_{\mathrm{DVMD}}$ & 0.000001 & 0.0000004 & rectangular & $1762.65 \mathrm{~cd}$ & 0.00071 & 0.0002 \\
\hline$U_{\mathrm{L}}$ & $0.584720 \mathrm{~V}$ & $0.0000036 \mathrm{~V}$ & normal & $3014.50 \frac{\mathrm{cd}}{\mathrm{V}}$ & 0.01085 & 0.04 \\
\hline$U_{\mathrm{L}}(J)$ & $5.8472 \mathrm{~A}$ & $0.0006 \mathrm{~A}$ & normal & $-301.45 \frac{\mathrm{cd}}{\mathrm{A}}$ & -0.18087 & 10.3 \\
\hline$R$ & $0.099994 \Omega$ & $0.0000020 \Omega$ & normal & $-17627.44 \frac{\mathrm{cd}}{\Omega}$ & -0.03525 & 0.4 \\
\hline$R_{\mathrm{D}}$ & $-0.0000010 \Omega$ & $0.0000004 \Omega$ & rectangular & $-1762.64 \frac{\mathrm{cd}}{\Omega}$ & -0.00071 & 0.0002 \\
\hline$\alpha_{\mathrm{RS}} \Delta T$ & 0.0 & 0.0000023 & rectangular & $-1762.64 \mathrm{~cd}$ & -0.00407 & 0.01 \\
\hline$m_{\mathrm{i}}$ & 6.24 & 0.14 & rectangular & $-0.00662 \mathrm{~cd}$ & 0.00096 & 0.0003 \\
\hline$d$ & $4.000 \mathrm{~m}$ & $0.00018 \mathrm{~m}$ & rectangular & $141.16 \frac{\mathrm{cd}}{\mathrm{m}}$ & 0.02541 & 0.2 \\
\hline$d_{\mathrm{p}}$ & $0.00212 \mathrm{~m}$ & $0.000021 \mathrm{~m}$ & rectangular & $141.16 \frac{\mathrm{cd}}{\mathrm{m}}$ & 0.00296 & 0.003 \\
\hline$\alpha_{\mathrm{RS}} \Delta T$ & 0.0 & 0.0000078 & rectangular & $141.16 \mathrm{~cd}$ & 0.00110 & 0.0004 \\
\hline$P_{\mathrm{c}}$ & $221.12 \mathrm{nA}$ & $0.024 \mathrm{nA}$ & normal & $1.27 \frac{\mathrm{cd}}{\mathrm{nA}}$ & 0.03007 & 0.3 \\
\hline$c_{\mathrm{PCM}}$ & 1.00033 & 0.00010 & normal & $1.27 \mathrm{~cd}$ & 0.00013 & 0.00001 \\
\hline$c_{\mathrm{PCMD}}$ & -0.000030 & 0.000012 & rectangular & $1.27 \mathrm{~cd}$ & 0.00002 & 0.0000001 \\
\hline$s_{\mathrm{v}}$ & $12.592 \frac{\mathrm{nA}}{1 \mathrm{x}}$ & $0.019 \frac{\mathrm{nA}}{1 \mathrm{x}}$ & normal & $-22.44 \mathrm{~cd} \frac{\mathrm{lx}}{\mathrm{nA}}$ & -0.42391 & 56.3 \\
\hline$s_{\mathrm{vD}}$ & -0.0006 & 0.0024 & rectangular & $-22.44 \mathrm{~cd}$ & -0.05386 & 0.9 \\
\hline$c c f$ & 1.0000 & 0.0005 & rectangular & $282.47 \mathrm{~cd}$ & 0.14124 & 6.3 \\
\hline$s c f$ & 0.9992 & 0.0004 & normal & $282.70 \mathrm{~cd}$ & 0.11308 & 4.0 \\
\hline$M_{\mathrm{R}}$ & 0.9998 & 0.00006 & normal & $282.54 \mathrm{~cd}$ & 0.01783 & 0.1 \\
\hline$L_{a \epsilon}$ & $0.0^{\circ}$ & $0.00064^{\circ}$ & rectangular & $-282.47 \frac{\mathrm{cd}}{\mathrm{o}}$ & -0.18103 & 10.3 \\
\hline$L_{a \phi}$ & $0.0^{\circ}$ & $0.00064^{\circ}$ & rectangular & $-282.47 \frac{\mathrm{cd}}{\mathrm{o}}$ & -0.18103 & 10.3 \\
\hline$P_{\theta}$ & $0.0^{\circ}$ & $0.00012^{\circ}$ & rectangular & $-282.47 \frac{\mathrm{cd}}{\mathrm{o}}$ & -0.03262 & 0.3 \\
\hline$P_{\mathrm{N}}$ & 0.0 & 0.00012 & rectangular & $-282.47 \mathrm{~cd}$ & -0.03390 & 0.4 \\
\hline$I_{\mathrm{LUC}}$ & $281.20 \mathrm{~cd}$ & & \multicolumn{2}{|c|}{$\begin{array}{l}\text { combined uncertainty, } u ; k=1 \\
\text { effective degree of freedom, } v_{\text {eff }} \\
\text { expanded uncertainty, } U ; k=2 \\
\text { expanded uncertainty, } U ; k=2\end{array}$} & $\begin{array}{c} \pm 0.56 \mathrm{~cd} \\
>100 \\
\pm 1.13 \mathrm{~cd} \\
0.4 \%\end{array}$ & \\
\hline
\end{tabular}

a RTD and estimated as $u\left(R_{\mathrm{D}}\right)=s\left(R_{\mathrm{D}}\right) / \sqrt{3}=0.0000004$. The temperature coefficient of the reference resistor is stated by the manufacturer as $4 \times 10^{-6} /{ }^{\circ} \mathrm{C}$. The environmental conditions of the laboratory are stable and controlled over the time (the temperature of the laboratory for example is $23^{\circ} \mathrm{C} \pm 1^{\circ} \mathrm{C}$ ). Thus, the resistance variation of the reference shunt resistor due to a temperature variation $\left( \pm 1^{\circ} \mathrm{C}\right)$ was estimated to be within $\pm 0.000004 \Omega$ using known formula $R=R_{0}+\alpha\left(T-T_{0}\right)$, which causes the standard uncertainty of $u(\alpha \Delta T)=0.0000023$ assuming a RTD.

Exponent for changes of lamp current affecting the luminous intensity for incandescent lamps was taken as $m_{\mathrm{i}}=6.24 \pm 0.25[7,8]$. The developed software by LabView was used to operate and to monitor electrical parameters of the LUC during the calibration process. The luminous intensity calibration was carried out after stabilization of the LUC current. The voltage drop across the reference shunt resistor during whole calibration process was obtained from the arithmetic mean of 20 readings $(v=19)$ as $0.584720 \mathrm{~V}$. The relative standard deviation of repeated measurements $(n=20)$ was used as the standard uncertainty $\left(u\left(U_{\mathrm{L}}\right)=\right.$ 
$0.0000036 \mathrm{~V}$ ) assuming a normal type of distribution (NTD), where degree of freedom of this estimate was equal to $\nu_{V}=19$.

The distance in the calibration was aligned to $\approx 4 \mathrm{~m}$ by measuring it in two stages: (i) the distance between the filament plane of the lamp and the outermost surface of the photometer $(d)$ and (ii) the distance offset of the photometer $\left(d_{\mathrm{p}}\right)$. The first stage was measured mechanically by using a calibrated finest quality stainless steel ruler attached to the bench. The overall length of the ruler is $5 \mathrm{~m}$ and it had been calibrated at several points by comparing it with a reference bench system having calibrated line scale of $6 \mathrm{~m}$, which has been developed by Dimension Standards Laboratory of UME. The calibration certificate stated that ruler was calibrated with expanded uncertainty formula of $U(k=2)=\sqrt{0.05^{2}+(0.005 L)^{2}} \mathrm{~mm}$. This means that the uncertainty in the length scale is $4.000 \mathrm{~m} \pm 0.054 \mathrm{~mm}(k=2)$. The worst case was considered for uncertainty analysis $(\approx 0.3 \mathrm{~mm})$ because it was assumed that there may be a deviation as for the thickness of the line showing the distance on the ruler. Thus, standard uncertainty for the distance measurement was assumed with a RTD and estimated as $u(d)=0.0003 / \sqrt{3}=0.00017 \mathrm{~m}$. The thermal expansion coefficient $\left(\alpha_{\mathrm{RS}} \Delta T\right)$ of the stainless steel ruler is stated by the manufacturer as $17 \times 10^{-6} /{ }^{\circ} \mathrm{C}$. Thus, the length variation of the stainless ruler due to a temperature variation within the laboratory was estimated to be within $\partial L / \partial T= \pm 0.000014 \mathrm{~m}$. It causes the negligible standard uncertainty of $u\left(\alpha_{\mathrm{RS}} \Delta T\right)=0.0000078$ assuming a RTD. The second stage of the distance measurement, which is equal to the distance from the outermost surface of the RP and its aperture plane (acceptance are of the RP), had been measured at the Dimensional Laboratory of UME using a Coordinate Measuring Machine and found to be $2.12 \mathrm{~mm} \pm 0.02 \mathrm{~mm}(k=2)$. It causes a standard uncertainty of $u\left(d_{\mathrm{p}}\right)=0.000021 \mathrm{~m}$ assuming a NTD.

The luminous intensity value of the LUC was measured by using a thermostabilized commercial RP, manufactured by PRC Krochmann GmbH (TH15BA). The RP consists basically of a well-defined input aperture having nominal area of $0.5 \mathrm{~cm}^{2}$ that defines the solid angle and the distance measurement plane, the matching filter $V(\lambda)$ and a Si photodiode. All these components are assembled in a temperature-controlled cylindrical housing. Inside the housing the temperatures of the Si photodiode and the filter are kept constant at $35^{\circ} \mathrm{C}$ during operation time in order to eliminate the influence of the surrounding temperature. The temperature regulation occurs within the $\mathrm{RP}$ with special control electronics $\left(f_{6}<0.2 \%\right)$ [9].

The $s_{\mathrm{v}}$ of the RP is equal to $s_{\mathrm{v}}=12.592 \mathrm{nA} / \mathrm{lx}$. The photometer head had been calibrated using new detector-based UME illuminance scale with expanded uncertainty of $0.30 \%(k=2)[5,6]$. Thus, the standard uncertainty in the illuminance responsivity value was estimated as $u\left(s_{\mathrm{v}}\right)=0.019 \mathrm{nA} / \mathrm{lx}$. The $\mathrm{RP}$ is recalibrated annually by comparing it with the absolutely calibrated filter radiometers constructed for the realization of the candela [5]. The drift of the illuminance responsivity value of the RP since its last calibration was estimated 
from its calibration history to be $-0.006 \mathrm{nA} / \mathrm{lx}(\approx 0.05 \%)$ with standard deviation of $s\left(s_{\mathrm{vD}}\right)=0.0042$. Thus, the standard uncertainty of the drift value was assumed with a RTD and estimated as $u\left(s_{\mathrm{vD}}\right)=s\left(s_{\mathrm{vD}}\right) / \sqrt{3}=0.0024 \mathrm{nA} / \mathrm{lx}$.

The photocurrent generated at the output of the RP was measured with the PRC-321 model as PCM. A mechanical shutter was used in front of the RP for taking real signal. The measured photocurrent was the average of 20 readings $(v=19)$ taken after the stabilization of the LUC current. Each reading was performed for the shutter opened $\left(P_{\mathrm{so}}\right)$ and closed (dark signal, $\left.P_{\mathrm{sc}}\right)$ conditions. The dark signal was subtracted from the reading $\left(P_{\mathrm{c}}=P_{\mathrm{so}}-P_{\mathrm{sc}}\right)$ in order to obtain the real photocurrent value $\left(P_{\mathrm{c}}\right)$. The standard uncertainty of the mean photocurrent reading of $221.12 \mathrm{nA}$ was obtained as $u\left(P_{\mathrm{c}}\right)=0.024 \mathrm{nA}$, which is the standard deviation of twenty readings. The PCM had been calibrated by Impedance Standards Laboratory of UME. The calibration certificate stated that calibration factor of the PCM for the current level from $100 \mathrm{nA}$ to $500 \mathrm{nA}$ was found to be $c_{\mathrm{PCM}}=1.00033$ with relative expanded uncertainty of $0.02 \%(k=2)$. Thus, the standard uncertainty was assumed with a NTD $\left(v_{i} \rightarrow \infty\right)$ and it was calculated as $u\left(c_{\mathrm{PCM}}\right)=(1.00033 \times 0.00020 / 2)=0.00010$. The PCM is recalibrated annually and the drift of the calibration factor of the PCM since its last calibration was estimated from its calibration history to be -0.000030 with standard deviation of $s\left(c_{\mathrm{PMCD}}\right)=0.000021$. Thus, the standard uncertainty of the drift value was estimated as $u\left(c_{\mathrm{PMCD}}\right)=s\left(c_{\mathrm{PMCD}}\right) / \sqrt{3}=0.000012$ assuming a RTD.

The $c c f$ is a function of the spectral power distribution of a light source. It is known that an error occurs when the photometer measures a light source having a spectral power distribution different from the calibrated source (CIE Illuminant A). The variations of the illuminance responsivities of the $\mathrm{RP}$ depend on the spectral power distributions of several type of light sources including tungsten filament incandescent, fluorescent, high-pressure sodium, and metal-halide light sources and white/colored light emitting diodes and they had been investigated [10]. The $c c f$ of the RP is equal to unity for the Osram Wi41/G type of light source operated at $2856 \mathrm{~K}$. The uncertainty of the $u(c c f)$ had been calculated as $u(c c f)=0.0005$ using square-root of sum of squares of the two relative spectral measurements on detector and lamp as well (relative spectral responsivity of the $\mathrm{RP}$ and the spectral distribution of the LUC) [10].

The $s c f$ is more problematic when a detector-based method is used. The stray light is generally obstructed by using a set of baffles between the light source and the photometer. The amount of stray light had been calculated as 0.9992 by taking mean ratio of photometer signals at lamp off and lamp on (by masking only the photometer) conditions. Thus, the experimental standard deviation of repeated measurements $\left(n=20, \nu_{V}=19\right)$ was used as the standard uncertainty of stray light measurements $(u(s c f)=0.0004)$ assuming a NTD.

The luminous intensity measurements were repeated six times by reoperation of the LUC at each time and then measurement results were normalized 
to unity. Then the repeatability was calculated by taking arithmetic mean of normalized luminous intensities $\left(R_{\mathrm{M}}=0.99978\right)$ and the standard uncertainty of the repeatability measurements was estimated from experimental standard deviation of results $\left(u\left(R_{\mathrm{M}}\right)=0.00006\right)$.

Both the LUC and the RP were mounted on alignment stages, each of which had five-degree of freedom for perpendicularity alignment. The LUC was mounted to the holder on the photometric bench in the base-down position and the horizontal $\left(L_{a \phi}\right)$ and vertical $\left(L_{a \epsilon}\right)$ alignments of the filament were performed using side-viewing precision transits (Brunson, 76-RH190). The first transit (Transit-1) was set up and aligned along a horizontal axis perpendicular to the laser beam whereas the second one (Transit-2) was set up on the optical axis and used for the vertical alignment. Perpendicularity alignments of the filament at both axes were performed using observed images of the filament from the transits. The manufacturer's specifications stated that each the transit has a resolution of 4.0 arcsecond $\left(0.001^{\circ}\right)$, which means that the alignments of the filament were estimated to be zero degree with limits of $\pm 0.001^{\circ}$. Thus, the standard uncertainty of each the alignment was estimated to be $u\left(L_{a \phi}\right)=u\left(L_{a \epsilon}\right)=0.00064^{\circ}$.

The perpendicularity alignment of the RP was performed before alignment of the LUC to the optical axis. The alignment was performed by using a laser diode having $1 \mathrm{~mm}$ output aperture that was used also for determining of the optical axis. Surface of the RP was closed with a lid having alignment mirror and then the laser beam was reflected back from the mirror. The maximum error in falling of the laser beam will inevitably/unavoidably be $\pm 0.5 \mathrm{~mm}$. The maximum error at the photometric distance of $5 \mathrm{~m}$ was calculated as $R P_{\theta}=2 \times \arctan (5000 / 0.5)=$ 0.0002 . Thus, the standard uncertainty of the RP alignment was estimated as $u\left(R P_{\theta}\right)=0.0002 / \sqrt{3}=0.00012^{\circ}$.

A detector is said to be linear if its output signal is directly proportional to the incident power. The linearity of the RP had been measured using a flux-addition technique [11]. Measurements had been performed between the photocurrents of $2 \mathrm{nA}$ and $2 \mathrm{~mA}$ by applying different neutral density filter combinations to the beam ways. In order to reduce the effects of random noise, the measurements had been repeated at least 10 times at each photocurrent level. Measurement result indicated that the RP is linear over an output current range of $10^{-9} \mathrm{~A}$ to $10^{-4} \mathrm{~A}$ with standard uncertainty of $0.012 \%(k=1)$, which corresponds to illuminance range of $8 \times 10^{-2} \mathrm{~lx}$ to $8 \times 10^{3} \mathrm{~lx}$. Therefore the RP can be used to measure the luminous intensity of a light source between $1.3 \mathrm{~cd}$ and $1.3 \times 10^{5}$ cd at $4 \mathrm{~m}$.

The next step for forming the uncertainty budget after determining of the standard uncertainties $u\left(x_{i}\right)$ was to calculate sensitivity coefficient $\left(c_{i}\right)$ of each the input quantity $\left(X_{i}\right)$ by taking the partial derivative of the model function $f$ (Eq. (6)) with respect to the input quantity (Table I). The $c_{i}$ coefficients are essentially conversion factors that allow to convert the units of an input quantity 
into the units of the measurand and express mathematically how much $f$ changes give an infinitesimal change in $x_{i}$. Detailed description for the calculating of the $c_{i}$ coefficient for each input quantity is described in Appendix A. Afterwards, uncertainty contribution for each quantity $u_{i}(y)$ was calculated and then the combined standard uncertainty $u_{\mathrm{c}}(y)$ was calculated as $u_{\mathrm{c}}\left(I_{\mathrm{LUC}}\right)= \pm 0.56 \mathrm{~cd}$ by taking the square root of sum of the uncertainty contributions. The expanded uncertainty of the luminous intensity calibration was estimated as $U\left(I_{\mathrm{LUC}}\right)= \pm 1.13 \mathrm{~cd}$ with level of confidence of $95.45 \%$ by multiplying the $u_{\mathrm{c}}\left(I_{\mathrm{LUC}}\right)$ by a coverage factor $k=2\left(\nu_{\text {eff }}>100\right)$. This estimation shows that the expanded uncertainty in the luminous intensity calibration within the interval from $1.3 \mathrm{~cd}$ to $1.3 \times 10^{5} \mathrm{~cd}$ is $0.4 \%$.

\subsection{Uncertainty evaluation in the luminous flux calibration}

Two-axial goniophotometer having a radius of $1.32 \mathrm{~m}$ had been constructed at UME for realizing the luminous flux unit of lumen absolutely with expanded uncertainty of $0.39 \%(k=2)$. A set of lamps having different shapes and powers was calibrated in this system in order to use them as WSL in the integrating sphere, which is the base of the routine luminous flux calibration setup.

The routine luminous flux calibration was carried out at UME using a substitution method in which the LUC was compared with the WSL within an integrating sphere [12]. The integrating sphere $(\phi=2 \mathrm{~m})$, inner surface of which is coated with a barium-sulfate paint, has a lamp holder (with a E27 lamp socket) at the center of the sphere, an auxiliary lamp, a baffle screen, a temperature sensor and a photometer installation port (Fig. 2). The photometer head with a cosine-corrected angular responsivity $(\mathrm{CPH})$ was installed to the sphere port to measure photometric signals.

The luminous flux calibration was carried out as follows: first, the auxiliary lamp was operated and after stabilization of the lamp current, the WSL and the LUC were separately installed to the lamp socket and self-absorption factors ( $P_{\mathrm{AWSL}}$ and $\left.P_{\mathrm{ALUC}}\right)$ were measured by the $\mathrm{CPH}$. Then the auxiliary lamp was turned off and the WSL was installed again to the center of the sphere and turned on. After stabilization of the lamp current, photometric signal $\left(P_{\mathrm{WSL}}\right)$ and inside temperature of the sphere $\left(t_{\mathrm{WSL}}\right)$ were measured. Then the WSL was replaced by the LUC and photocurrent and temperature readings $\left(P_{\mathrm{LUC}}\right.$ and $\left.t_{\mathrm{LUC}}\right)$ were repeated after stabilization of the LUC.

A tungsten filament lamp of type Polaron 200L having clear bulb was used for evaluating of the uncertainty in the luminous flux calibration. The lamp was operated at color temperature of $\approx 2700 \mathrm{~K}$. The luminous flux value $\left(\Phi_{\mathrm{WSL}}\right)$ of the LUC was then calculated using the following equation:

$$
\Phi_{\mathrm{LUC}}=\Phi_{\mathrm{WSL}} \frac{P_{\mathrm{LUC}}}{P_{\mathrm{WSL}}} \frac{P_{\mathrm{AWSL}}}{P_{\mathrm{ALUC}}} \frac{t_{\mathrm{LUC}}}{t_{\mathrm{WSL}}} c c f M_{\mathrm{R}},
$$

where $\Phi_{\mathrm{WSL}}$ is the luminous flux value of the WSL. 


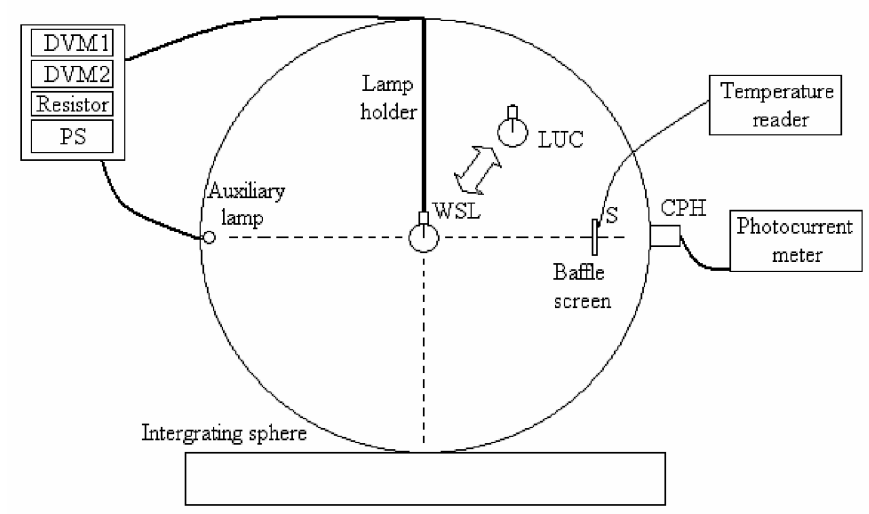

Fig. 2. The luminous flux calibration setup. WSL is the working standard lamp, LUC is the lamp under the calibration, CPH is the cosine-corrected photometer head, DVM1 and DVM2 are digital voltmeters, PS is the power supply and S is the temperature sensor.

An uncertainty model shown below was used for the evaluation of the uncertainty in the luminous flux calibration

$$
\begin{gathered}
\Phi_{\mathrm{LUC}}=\left[\frac{\left(c_{\mathrm{ADVM}}+c_{\mathrm{ADVMD}}\right) U_{\mathrm{A}}}{J_{\mathrm{A}} R_{\mathrm{A}}\left(1+R_{\mathrm{D}}+\alpha_{\mathrm{RS}} \Delta T\right)}\right]^{m_{\mathrm{i}}}\left(\frac{U_{\mathrm{LUC}}}{U_{\mathrm{WSL}}}\right) \Phi_{\mathrm{WSL}} \\
\times \frac{P_{\mathrm{LUC}}}{P_{\mathrm{WSL}}} \frac{P_{\mathrm{AWSL}}}{P_{\mathrm{ALUC}}} \frac{t_{\mathrm{LUC}}}{t_{\mathrm{WSL}}} c f M_{\mathrm{R}}\left(1-P_{\mathrm{N}}\right),
\end{gathered}
$$

where $c_{\mathrm{ADVM}}$ is the correction factor for DVM used in self-absorption factor measurements, $U_{\mathrm{A}}$ is the auxiliary voltage drop across a shunt resistor $\left(R_{\mathrm{A}}\right), J_{\mathrm{A}}$ is the auxiliary lamp current, $U_{\mathrm{LUC}}$ and $U_{\mathrm{WSL}}$ are voltage drops across a shunt resistor when the LUC and the WSL are operated.

Table II gives established uncertainty budget for the luminous flux calibration of an aged $200 \mathrm{~W}$ tungsten filament lamp of type Polaron 200L performed at UME.

In the self-absorption factor measurements an Osram lamp with tungsten filament having operating current of $3.8000 \pm 0.0004 \mathrm{~A}(k=1)$ was used as an auxiliary lamp. The electronic equipment that was used for the lamp control in the luminous intensity calibration (DVM, shunt resistor, dc power supply etc.) was also used in this setup. The voltage drop across the resistor $\left(U_{\mathrm{A}}\right)$ was monitored continuously during the measurement procedure and average value was found as $0.379981 \mathrm{~V}$. Thus, the relative standard deviation $(n=20$ and $v=19)$ of these measurements was used as a standard uncertainty $\left(u\left(U_{\mathrm{A}}\right)=0.000013 \mathrm{~V}\right)$.

Substitution method was used in the luminous flux calibration. First, standard lamp was operated and after the measurement procedure this lamp was replaced by the LUC. In each case voltage drops across the resistor $\left(U_{\mathrm{WSL}}\right.$ and $\left.U_{\text {LUC }}\right)$ were monitored continuously during the measurement procedure. Relative 
TABLE II

Uncertainty budget established at UME for the luminous flux calibration of a Polaron 200L type of optical light source.

\begin{tabular}{|c|c|c|c|c|c|c|}
\hline $\begin{array}{c}\text { Quantity } \\
X_{i}\end{array}$ & $\begin{array}{c}\text { Estimate } \\
x_{i}\end{array}$ & $\begin{array}{c}\text { Standard } \\
\text { uncertainty } \\
\qquad u\left(x_{i}\right)\end{array}$ & $\begin{array}{l}\text { Probability } \\
\text { distribution }\end{array}$ & $\begin{array}{c}\text { Sensitivity } \\
\text { coefficient } \\
c_{i}\end{array}$ & $\begin{array}{c}\text { Uncertainty } \\
\text { contribution } \\
u_{i}(y)[\mathrm{lm}]\end{array}$ & $\begin{array}{c}\text { Contribution } \\
\text { coefficient } \\
h\left(y, x_{i}\right)[\%]\end{array}$ \\
\hline$c_{\mathrm{ADVM}}$ & 0.999992 & 0.000004 & normal & $12350.62 \mathrm{~lm}$ & 0.04940 & 0.01 \\
\hline$c_{\mathrm{ADVMD}}$ & 0.000001 & 0.0000004 & rectangular & $12350.62 \mathrm{~lm}$ & 0.00494 & 0.0001 \\
\hline$U_{\mathrm{A}}$ & $0.379981 \mathrm{~V}$ & $0.000013 \mathrm{~V}$ & normal & $32503.02 \frac{\mathrm{lm}}{\mathrm{V}}$ & 0.42254 & 0.9 \\
\hline$J_{\mathrm{A}}$ & $3.8000 \mathrm{~A}$ & $0.0004 \mathrm{~A}$ & normal & $-3250.14 \frac{\mathrm{lm}}{\mathrm{A}}$ & -1.30006 & 8.5 \\
\hline$R_{\mathrm{A}}$ & $0.099994 \Omega$ & $0.0000020 \Omega$ & normal & $-123512.70 \frac{\mathrm{lm}}{\Omega}$ & -0.24703 & 0.3 \\
\hline$R_{\mathrm{D}}$ & $-0.0000010 \Omega$ & $0.0000004 \Omega$ & rectangular & $-12350.54 \frac{\mathrm{lm}}{\Omega}$ & -0.00494 & 0.0001 \\
\hline$\alpha_{\mathrm{RS}} \Delta \mathrm{T}$ & 0.0 & 0.0000023 & rectangular & $-12350.54 \mathrm{~lm}$ & -0.02841 & 0.004 \\
\hline$m_{\mathrm{i}}$ & 6.24 & 0.14 & rectangular & $0.003 \mathrm{~lm}$ & 0.00048 & 0.000001 \\
\hline$U_{\text {LUC }}$ & $0.190010 \mathrm{~V}$ & $0.0000067 \mathrm{~V}$ & normal & $10416.56 \frac{\mathrm{lm}}{\mathrm{V}}$ & 0.06979 & 0.02 \\
\hline$U_{\mathrm{WSL}}$ & $0.189991 \mathrm{~V}$ & $0.0000066 \mathrm{~V}$ & normal & $-10417.61 \frac{\mathrm{lm}}{\mathrm{V}}$ & -0.06876 & 0.02 \\
\hline$\Phi_{\mathrm{WSL}}$ & $1881.41 \mathrm{~lm}$ & $3.67 \mathrm{~lm}$ & normal & 1.05 & 3.86086 & 75.4 \\
\hline$P_{\mathrm{LUC}}$ & $1079.1 \mathrm{nA}$ & $0.27 \mathrm{nA}$ & normal & $1.83 \frac{\mathrm{lm}}{\mathrm{nA}}$ & 0.49523 & 1.2 \\
\hline$P_{\mathrm{WSL}}$ & $1033.3 \mathrm{nA}$ & $0.26 \mathrm{nA}$ & normal & $-1.92 \frac{\mathrm{lm}}{\mathrm{nA}}$ & -0.49802 & 1.3 \\
\hline$P_{\text {AWSL }}$ & $431.18 \mathrm{nA}$ & $0.11 \mathrm{nA}$ & normal & $4.59 \frac{\mathrm{lm}}{\mathrm{nA}}$ & 0.50493 & 1.3 \\
\hline$P_{\text {ALUC }}$ & $431.37 \mathrm{nA}$ & $0.11 \mathrm{nA}$ & normal & $-4.59 \frac{\mathrm{lm}}{\mathrm{nA}}$ & -0.50471 & 1.3 \\
\hline$t_{\mathrm{LUC}}$ & $24.321^{\circ} \mathrm{C}$ & $0.008^{\circ} \mathrm{C}$ & normal & $81.38 \frac{\mathrm{lm}}{{ }^{\circ} \mathrm{C}}$ & 0.65104 & 2.1 \\
\hline$t_{\mathrm{WSL}}$ & $24.117^{\circ} \mathrm{C}$ & $0.008^{\circ} \mathrm{C}$ & normal & $-82.07 \frac{\mathrm{lm}}{{ }^{\circ} \mathrm{C}}$ & -0.65655 & 2.2 \\
\hline$c c f$ & 0.9998 & 0.0005 & rectangular & $1979.65 \mathrm{~lm}$ & 0.98982 & 5.0 \\
\hline$M_{\mathrm{R}}$ & 0.99942 & 0.00008 & normal & $1980.40 \mathrm{~lm}$ & 0.15843 & 0.1 \\
\hline$P_{\mathrm{N}}$ & 0.0 & 0.00012 & rectangular & $-1979.25 \operatorname{lm}$ & -0.23751 & 0.3 \\
\hline$\Phi_{\mathrm{LUC}}$ & $1979.25 \mathrm{~lm}$ & & \multicolumn{2}{|c|}{$\begin{array}{l}\text { combined uncertainty, } u ; k=1 \\
\text { effective degree of freedom, } v_{\text {eff }} \\
\text { expanded uncertainty, } U ; k=2 \\
\text { expanded uncertainty, } U ; k=2\end{array}$} & $\begin{array}{c} \pm 4.45 \mathrm{~lm} \\
>100 \\
\pm 8.89 \mathrm{~lm} \\
0.5 \%\end{array}$ & \\
\hline
\end{tabular}

standard deviations ( $n=20$ and $v=19$ ) of measurements were used as standard uncertainties $\left(u\left(U_{\mathrm{WSL}}\right)=0.0000066 \mathrm{~V}\right.$ and $\left.u\left(U_{\mathrm{LUC}}\right)=0.0000067 \mathrm{~V}\right)$.

The luminous flux value of the WSL had been calibrated at UME using a constructed two-axial goniophotometer. Each arm of the goniophotometer acts using high performance dc servomotor-based rotational stages. Spatial illuminance distribution values of the WSL in the polar coordinate system had been used in the luminous flux calculation. The overall uncertainty in the realization of the luminous flux unit had been obtained with expanded uncertainty of $0.39 \%(k=2)$, which causes uncertainty of $u\left(\Phi_{\mathrm{WSL}}\right)=3.67 \mathrm{~lm}$.

The thermostabilized $\mathrm{CPH}$ attached to the photometer port of the integrating sphere was used in self-absorption factor measurements ( $P_{\text {AWSL }}$ and $\left.P_{\text {ALUC }}\right)$ and in measurement of signals produced by the WSL and the LUC ( $P_{\mathrm{WSL}}$ and $\left.P_{\text {LUC }}\right)$. The generated photocurrent during each measurement was measured with a calibrated photocurrent meter. Uncertainty of each photocurrent reading, which is shown in Table II, was obtained from the standard deviation of twelve $(v=12)$ measurements.

Temperature measurement inside the sphere carries vital importance because reflectance of the sphere coating depends on the temperature. During the luminous flux measurements temperature was monitored using a calibrated 
Pt-100 sensor. Temperature readings $\left(t_{\mathrm{WSL}}\right.$ and $\left.t_{\mathrm{LUC}}\right)$ were recorded simultaneously when the photometer head measured $P_{\mathrm{WSL}}$ and $P_{\mathrm{LUC}}$ and relative standard deviation of measurements $(v=11)$ were used as standard uncertainty in the temperature measurements.

The detailed description for the calculating of the $c_{i}$ coefficient for each input quantity (Table II) in the luminous flux calibration is described in Appendix B. The expanded uncertainty $u_{\mathrm{c}}(y)$ of the luminous flux calibration was calculated as $u_{\mathrm{c}}\left(\Phi_{\mathrm{LUC}}\right)= \pm 8.89 \mathrm{~lm}$ with level of confidence of $95.45 \%\left(k=2, \nu_{\mathrm{eff}}>100\right)$.

\subsection{Uncertainty evaluation in the luminance calibration}

The photometric bench system depicted in Fig. 1 was used for calibrating of a luminance of the light source or a luminance of sphere (LSUC). The CPH and a calibrated aperture were used in the calibration. The optical axis was determined by using a laser beam. The circular aperture having nominal diameter of $A=20 \mathrm{~mm}$ was used in front of the port of the LSUC for defining the luminance area [13]. The CPH was located at the appropriate photometric distance $(d)$ from the aperture of the LSUC and the illuminance value $\left(E_{\mathrm{LSUC}}\right)$ was determined by dividing the generated photocurrent $\left(P_{\mathrm{c}}\right)$ at the output of the $\mathrm{CPH}$ by its illuminance responsivity $\left(s_{\mathrm{v}}\right)$. Then the luminous intensity of the LSUC $\left(I_{\mathrm{LSUC}}\right)$ was calculated by multiplying the $E_{\mathrm{LSUC}}$ by the $d$. Finally, the luminance value ( $\left.L_{\mathrm{LSUC}}\right)$ was determined by dividing the $I_{\mathrm{LSUC}}$ by the area of the $A$ :

$$
L_{\mathrm{LSUC}}=\frac{d^{2} P_{\mathrm{c}}}{s_{\mathrm{v}} A} c c f \text {. }
$$

An uncertainty model shown below was used for evaluating of the uncertainty in the luminance calibration

$$
\begin{aligned}
& L_{\mathrm{LSUC}}=\frac{\left(d+d_{\mathrm{p}}+\alpha_{\mathrm{RS}} \Delta T\right)^{2}}{A}\left[\frac{\left(P_{\mathrm{c}}+c_{\mathrm{PCM}}+c_{\mathrm{PCMD}}\right)}{\left(s_{\mathrm{v}}+s_{\mathrm{vD}}\right)}\right] \operatorname{ccf} \operatorname{scf} M_{\mathrm{R}} \\
& \times\left(1-L S_{a \epsilon}-P_{a \theta}-P_{\mathrm{N}}\right),
\end{aligned}
$$

where $L S_{a \epsilon}$ is the perpendicularity alignment of the LSUC.

Table III gives established uncertainty budget for the luminance calibration of an aged luminance-source of type LN3 $(\approx 2850 \mathrm{~K})$ manufactured by LMT Lichtmesstechnik GmbH.

The distance is one of the important parameters because the luminous intensity of the LSUC was calculated using values of the distance and the illuminance. The distance was aligned to $1.1470 \mathrm{~m}$ by measuring it in two stages: (i) the distance between the center of the aperture of the LSUC and the outermost surface of the $\mathrm{CPH}(d)$ and (ii) the distance offset of the photometer $\left(d_{\mathrm{p}}\right)$. The first stage was measured mechanically by using a calibrated ruler $\left(\alpha_{\mathrm{RS}} \Delta T=17 \times 10^{-6} /{ }^{\circ} \mathrm{C}\right)$ as it was done in the luminous intensity calibration. The worst case was considered for uncertainty analysis $(\approx 0.3 \mathrm{~mm})$ because it was assumed that there may be a deviation as for the thickness of the line showing the distance on the ruler. Thus, standard uncertainty for the distance measurement was assumed with a 
TABLE III

Uncertainty budget established at UME for the luminance calibration of a LMT LN3 type of luminance source.

\begin{tabular}{|c|c|c|c|c|c|c|}
\hline $\begin{array}{c}\text { Quantity } \\
X_{i}\end{array}$ & $\begin{array}{c}\text { Estimate } \\
x_{i}\end{array}$ & $\begin{array}{c}\text { Standard } \\
\text { uncertainty } \\
u\left(x_{i}\right)\end{array}$ & $\begin{array}{l}\text { Probability } \\
\text { distribution }\end{array}$ & $\begin{array}{c}\text { Sensitivity } \\
\text { coefficient } \\
c_{i}\end{array}$ & $\begin{array}{c}\text { Uncertainty } \\
\text { contribution } \\
u_{i}(y) \frac{[\mathrm{cd}}{\left.\mathrm{m}^{2}\right]}\end{array}$ & $\begin{array}{c}\text { Contribution } \\
\text { coefficient } \\
h\left(y, x_{i}\right)[\%]\end{array}$ \\
\hline$d$ & $1.1500 \mathrm{~m}$ & $0.00017 \mathrm{~m}$ & rectangular & $1872.66 \frac{\mathrm{cd}}{\mathrm{m}^{3}}$ & 0.31835 & 1.8 \\
\hline$d_{\mathrm{p}}$ & $0.0030 \mathrm{~m}$ & $0.00001 \mathrm{~m}$ & rectangular & $1872.66 \frac{\mathrm{cd}}{\mathrm{m}^{3}}$ & 0.02622 & 0.01 \\
\hline$\alpha_{\mathrm{RS}} \Delta T$ & 0.0 & 0.0000078 & rectangular & $1872.66 \frac{\mathrm{cd}}{\mathrm{m}^{2}}$ & 0.01461 & 0.004 \\
\hline A & $\begin{array}{c}0.00070890 \\
\mathrm{~m}^{2}\end{array}$ & $\begin{array}{c}0.00000005 \\
\mathrm{~m}^{2}\end{array}$ & normal & $\begin{array}{c}-1522904.31 \\
\frac{\mathrm{cd}}{\mathrm{m}^{4}}\end{array}$ & -0.07615 & 0.1 \\
\hline$P_{\mathrm{c}}$ & $0.05390 \mathrm{nA}$ & $0.000005 \mathrm{nA}$ & normal & $\begin{array}{c}1024.08 \\
\mathrm{~cd}\end{array}$ & 0.00512 & 0.0005 \\
\hline$c_{\mathrm{PCM}}$ & 1.00033 & 0.00010 & normal & $\begin{array}{c}\overline{\mathrm{nAm}^{2}} \\
1024.08 \frac{\mathrm{cd}}{\mathrm{m}^{2}}\end{array}$ & 0.10241 & 0.2 \\
\hline$c_{\mathrm{PCMD}}$ & -0.000030 & 0.000012 & rectangular & $1024.08 \frac{\mathrm{cd}}{\mathrm{m}^{2}}$ & 0.01229 & 0.003 \\
\hline$s_{\mathrm{v}}$ & $1.8300 \frac{\mathrm{nA}}{1 \mathrm{x}}$ & $0.0027 \frac{\mathrm{nA}}{1 \mathrm{x}}$ & normal & $\begin{array}{l}-590.20 \\
\text { cdlx } \\
\end{array}$ & -1.59353 & 45.8 \\
\hline$s_{\mathrm{vD}}$ & -0.0008 & 0.0026 & rectangular & $\begin{array}{l}\text { nAm } \\
-590.20 \frac{\mathrm{cd}}{\mathrm{m}^{2}}\end{array}$ & -1.53451 & 42.5 \\
\hline$c c f$ & 1.0000 & 0.0005 & rectangular & $1079.59 \frac{\mathrm{cd}}{\mathrm{m}^{2}}$ & 0.53979 & 5.3 \\
\hline$s c f$ & 0.9993 & 0.0004 & normal & $1080.34 \frac{\mathrm{cd}}{\mathrm{m}^{2}}$ & 0.43214 & 3.4 \\
\hline$M_{\mathrm{R}}$ & 0.9996 & 0.00007 & normal & $1080.02 \frac{\mathrm{cd}}{\mathrm{m}^{2}}$ & 0.07560 & 0.1 \\
\hline$L S_{a \epsilon}$ & $0.0^{\circ}$ & $0.00012^{\circ}$ & rectangular & $-1079.59 \frac{\mathrm{cd}}{\mathrm{om}^{2}}$ & -0.12955 & 0.3 \\
\hline$P_{a \theta}$ & $0.0^{\circ}$ & $0.00012^{\circ}$ & rectangular & $-1079.59 \frac{\mathrm{cd}}{\mathrm{od}^{2}}$ & -0.12955 & 0.3 \\
\hline$P_{\mathrm{N}}$ & 0.0 & 0.00012 & rectangular & $-1079.59 \frac{\mathrm{cd}}{\mathrm{m}^{2}}$ & -0.12955 & 0.3 \\
\hline$L_{\mathrm{LSUC}}$ & $1079.59 \frac{\mathrm{cd}}{\mathrm{m}^{2}}$ & & \multicolumn{2}{|c|}{$\begin{array}{l}\text { combined uncertainty, } u ; k=1 \\
\text { effective degree of freedom, } \nu_{\text {eff }} \\
\text { expanded uncertainty, } U ; k=2 \\
\text { expanded uncertainty, } U ; k=2\end{array}$} & $\begin{array}{l} \pm 2.36 \frac{\mathrm{cd}}{\mathrm{m}^{2}} \\
>100 \\
\pm 4.71 \frac{\mathrm{cd}}{\mathrm{m}^{2}} \\
\quad 0.4 \%\end{array}$ & \\
\hline
\end{tabular}

RTD and estimated as $u(d)=0.0003 / \sqrt{3}=0.00017 \mathrm{~m}$. The second stage of the distance measurement, which is equal to the distance from the outermost surface of the $\mathrm{CPH}$ and its front cosine-corrected diffuser, had been measured at the Dimensional Laboratory of UME using a Coordinate Measuring Machine and found to be $3.00 \mathrm{~mm} \pm 0.03 \mathrm{~mm}(k=2)$. It causes standard uncertainty of $u\left(d_{\mathrm{p}}\right)=0.000014 \mathrm{~m}$ assuming a NTD.

The LSUC has a circular opening (diffusing surface) with diameter of $70 \mathrm{~mm}$ [13]. Calibrated black-anodized aluminum aperture with diameter of $20.012 \mathrm{~mm}$ was placed close to the opening of the LSUC to define the area. The inner wall of the aperture $(A)$ has sharp edge with angle of $45^{\circ}$. The diameter of the aperture had been calibrated by the Dimensional Laboratory of UME with relative standard uncertainty of $0.005 \mathrm{~mm}(k=2)$. Thus, the standard uncertainty in the aperture area was determined as $u(A)=(0.020012 \times 0.000005 / 2)=0.00000005$.

The luminous intensity value of the LSUC was measured by using the thermostabilized $\mathrm{CPH}$ and the photocurrent generated at its output was measured with the PRC-321 model as PCM. The illuminance responsivity $\left(s_{\mathrm{v}}\right)$ of the $\mathrm{CPH}$ is $s_{\mathrm{v}}=1.8300 \mathrm{nA} / \mathrm{lx}$ and it had been calibrated using new detector-based UME illuminance scale with expanded uncertainty of $0.30 \%(k=2)[5]$. 
Thus, the standard uncertainty in the illuminance responsivity value was estimated as $u\left(s_{\mathrm{v}}\right)=0.0027 \mathrm{nA} / \mathrm{lx}$. The $\mathrm{CPH}$ is recalibrated annually by comparing it with the absolutely calibrated filter radiometers constructed for the realization of the candela [5]. The drift of the illuminance responsivity value of the $\mathrm{CPH}$ since its last calibration was estimated from its calibration history to be $-0.0008 \mathrm{nA} / \mathrm{lx}$ with standard deviation of $s\left(s_{\mathrm{vD}}\right)=0.0045$. Thus, the standard uncertainty of the drift value was assumed with a RTD and estimated as $u\left(s_{\mathrm{vD}}\right)=s\left(s_{\mathrm{vD}}\right) / \sqrt{3}=0.0026 \mathrm{nA} / \mathrm{lx}$.

Perpendicularity alignments of both the CPH and the LSUC were carried out as follows. Each device was oriented to the optical axis and its alignment was carried out using a flat mirror and a laser diode having $1 \mathrm{~mm}$ output aperture. The laser beam was reflected back from the mirror mounted on the center of the opening of the device. The maximum error in falling of the laser beam onto the output point will inevitably/unavoidably be $\pm 0.5 \mathrm{~mm}$. The maximum error at the photometric distance of $5 \mathrm{~m}$ was calculated as $2 \arctan (5000 / 0.5)=0.0002$. Thus, the standard uncertainty of each the alignment was estimated as $u\left(L S_{a \phi}\right)=$ $u\left(P_{a \theta}\right)=0.0002 / \sqrt{3}=0.00012^{\circ}$.

The detailed description for the calculating of the $c_{i}$ coefficient for each the input quantity (Table III) in the luminance source calibration is described in Appendix C. The expanded uncertainty $u_{\mathrm{c}}(y)$ of the calibration was calculated as $u_{\mathrm{c}}\left(L_{\mathrm{LSUC}}\right)= \pm 4.66 \mathrm{~cd} / \mathrm{m}^{2}$ with level of confidence of $95.45 \%\left(k=2, \nu_{\mathrm{eff}}>100\right)$.

\section{Conclusions}

The uncertainty analyses in the photometric calibrations were studied. The uncertainty budgets given in Tables I to III showed that the best measurement capability of the UME in the luminous intensity, luminous flux and luminance calibrations were $0.4 \%, 0.5 \%$ and $0.4 \%$ with the standard coverage factors of $k=2$ (the degrees of freedom in output quantities were higher than 100), respectively. The validity of the expanded uncertainties covers calibrations of the luminous intensity of light sources from $1 \mathrm{~cd}$ to $10000 \mathrm{~cd}$, the luminous flux from $5 \mathrm{~lm}$ to $5000 \mathrm{~lm}$ and the luminance from $1 \mathrm{~cd} / \mathrm{m}^{2}$ to $10000 \mathrm{~cd} / \mathrm{m}^{2}$.

It was also found that the dominant component of the combined uncertainty in the detector-based calibrations (the luminous intensity and the luminance) was the uncertainty associated with the illuminance responsivity of the photometer $\left(h\left(y, x_{i}\right)=56.3 \%\right.$ and $h\left(y, x_{i}\right)=45.8 \%$, respectively). However, the dominant component in the luminous flux calibration was the uncertainty associated with the luminous flux value of the working standard lamp $\left(h\left(y, x_{i}\right)=75.4 \%\right)$.

\section{Appendix A: Determination of sensitivity coefficients for the luminous intensity calibration}

The sensitivity coefficient for each input quantity, given in Table I, was calculated by taking the partial derivative of the model function $f$ with respect to 
the input quantity using model equation (Eq. (6)). For the simplification of the equation, the following abbreviations may be accepted:

$$
\begin{aligned}
& \left(d+d_{\mathrm{p}}+\alpha_{\mathrm{RS}} \Delta T\right)=D, \quad\left(P_{\mathrm{c}}+c_{\mathrm{PCM}}+c_{\mathrm{PCMD}}\right)=P, \\
& \left(1-L_{a \epsilon}-L_{a \phi}-P_{a \theta}-P_{\mathrm{N}}\right)=A, \\
& \left(\frac{\left(c_{\mathrm{DVM}}+c_{\mathrm{DVMD}}\right) U_{\mathrm{L}}}{U_{\mathrm{L}}(J) R\left(1+R_{\mathrm{D}}+\alpha_{\mathrm{RS}} \Delta T\right)}\right)=L .
\end{aligned}
$$

Thus, the sensitivity coefficient of each input quantity will be calculated as follows: (i) Sensitivity coefficients for the calibration factor $\left(c_{\mathrm{DVM}}\right)$ and short-term drift $\left(c_{\text {DVMD }}\right)$ of the DVM

$$
\begin{aligned}
c_{c_{\mathrm{DVM}}} & =c_{c_{\mathrm{DVMD}}}=\frac{\partial I_{\mathrm{LUC}}(T)}{\partial c_{\mathrm{DVM}}}=\frac{\partial I_{\mathrm{LUC}}(T)}{\partial c_{\mathrm{DVMD}}} \\
= & \frac{c c f D^{2} m_{\mathrm{i}} M_{\mathrm{R}} P A s c f U_{\mathrm{L}} L^{-1+m_{\mathrm{i}}}}{U_{\mathrm{L}}(J) R\left(1+R_{\mathrm{D}}+\alpha_{\mathrm{RS}} \Delta T\right)\left(s_{\mathrm{v}}+s_{\mathrm{VD}}\right)} .
\end{aligned}
$$

(ii) Sensitivity coefficient for the voltage drop $\left(U_{\mathrm{L}}\right)$ :

$$
c_{U_{\mathrm{L}}}=\frac{\partial I_{\mathrm{LUC}}(T)}{\partial U_{\mathrm{L}}}=\frac{c c f\left(c_{\mathrm{DVM}}+c_{\mathrm{DVMD}}\right) D^{2} m_{\mathrm{i}} M_{\mathrm{R}} P A s c f L^{-1+m_{\mathrm{i}}}}{U_{\mathrm{L}}(J) R\left(1+R_{\mathrm{D}}+\alpha_{\mathrm{RS}} \Delta T\right)\left(s_{\mathrm{v}}+s_{\mathrm{VD}}\right)} .
$$

(iii) Sensitivity coefficient for the operating current $U_{\mathrm{L}}(J)$ of the LUT:

$$
\begin{aligned}
c_{U_{\mathrm{L}}(J)} & =\frac{\partial I_{\mathrm{LUC}}(T)}{\partial U_{\mathrm{L}}(J)} \\
= & -\frac{c c f\left(c_{\mathrm{DVM}}+c_{\mathrm{DVMD}}\right) D^{2} m_{\mathrm{i}} M_{\mathrm{R}} P A s c f U_{\mathrm{L}} L^{-1+m_{\mathrm{i}}}}{U_{\mathrm{L}}(J)^{2} R\left(1+R_{\mathrm{D}}+\alpha_{\mathrm{RS}} \Delta T\right)\left(s_{\mathrm{V}}+s_{\mathrm{VD}}\right)} .
\end{aligned}
$$

(iv) Sensitivity coefficient for the resistance value $(R)$ of the reference shunt resistor

$$
c_{R}=\frac{\partial I_{\mathrm{LUC}}(T)}{\partial R}=-\frac{c c f\left(c_{\mathrm{DVM}}+c_{\mathrm{DVMD}}\right) D^{2} m_{\mathrm{i}} M_{\mathrm{R}} P A s c f U_{\mathrm{L}} L^{-1+m_{\mathrm{i}}}}{U_{\mathrm{L}}(J) R^{2}\left(1+R_{\mathrm{D}}+\alpha_{\mathrm{RS}} \Delta T\right)\left(s_{\mathrm{v}}+s_{\mathrm{vD}}\right)} .
$$

(v) Sensitivity coefficients for the short-term drift $\left(R_{\mathrm{D}}\right)$ and the temperature coefficient $\left(\alpha_{\mathrm{RS}} \Delta T\right)$ of the reference shunt resistor

$$
\begin{aligned}
c_{R_{\mathrm{D}}} & =c_{\alpha_{\mathrm{RS}} \Delta \mathrm{T}}=\frac{\partial I_{\mathrm{LUC}}(T)}{\partial R_{\mathrm{D}}}=\frac{\partial I_{\mathrm{LUC}}(T)}{\partial \alpha_{\mathrm{RS}} \Delta T} \\
& =-\frac{c c f\left(c_{\mathrm{DVM}}+c_{\mathrm{DVMD}}\right) D^{2} m_{\mathrm{i}} M_{\mathrm{R}} P A s c f U_{\mathrm{L}} L^{-1+m_{\mathrm{i}}}}{U_{\mathrm{L}}(J) R\left(1+R_{\mathrm{D}}+\alpha_{\mathrm{RS}} \Delta T\right)^{2}\left(s_{\mathrm{v}}+s_{\mathrm{VD}}\right)} .
\end{aligned}
$$

(vi) Sensitivity coefficients for the exponent $\left(m_{\mathrm{i}}\right)$ :

$$
c_{m_{\mathrm{i}}}=\frac{\partial I_{\mathrm{LUC}}(T)}{\partial m_{\mathrm{i}}}=\frac{\operatorname{ccf} D^{2} M_{\mathrm{R}} P A s c f L^{m_{\mathrm{i}}} \log (L)}{\left(s_{\mathrm{v}}+s_{\mathrm{vD}}\right)} .
$$

(vii) Sensitivity coefficients for the photometric distance $(d)$, offset distance $\left(d_{\mathrm{p}}\right)$ and thermal expansion coefficient $\left(\alpha_{\mathrm{RS}} \Delta T\right)$ of the ruler

$$
c_{d}=c_{d_{\mathrm{p}}}=c_{\alpha_{\mathrm{RS}} \Delta T}=\frac{\partial I_{\mathrm{LUC}}(T)}{\partial d}=\frac{\partial I_{\mathrm{LUC}}(T)}{\partial d_{\mathrm{p}}}=\frac{\partial I_{\mathrm{LUC}}(T)}{\partial \alpha_{\mathrm{RS}} \Delta T}
$$




$$
=\frac{2 c c f D M_{\mathrm{R}} P A s c f L^{m_{\mathrm{i}}}}{\left(s_{\mathrm{v}}+s_{\mathrm{vD}}\right)} .
$$

(viii) Sensitivity coefficients for the photocurrent reading $\left(P_{\mathrm{c}}\right)$, calibration factor $\left(c_{\mathrm{PCM}}\right)$ and short-term drift $\left(c_{\mathrm{PCMD}}\right)$ of the PCM:

$$
\begin{aligned}
c_{P_{\mathrm{c}}} & =c_{c_{\mathrm{PCM}}}=c_{c_{\mathrm{PCMD}}}=\frac{\partial I_{\mathrm{LUC}}(T)}{\partial P_{\mathrm{c}}}=\frac{\partial I_{\mathrm{LUC}}(T)}{\partial c_{\mathrm{PCM}}}=\frac{\partial I_{\mathrm{LUC}}(T)}{\partial c_{\mathrm{PCMD}}} \\
& =\frac{c c f D^{2} M_{\mathrm{R}} A s c f L^{m_{\mathrm{i}}}}{\left(s_{\mathrm{v}}+s_{\mathrm{vD}}\right)} .
\end{aligned}
$$

(ix) Sensitivity coefficients for the illuminance responsivity $\left(s_{\mathrm{v}}\right)$ and short-term drift $\left(s_{\mathrm{vD}}\right)$ of the RP:

$$
c_{s_{\mathrm{v}}}=c_{s_{\mathrm{vD}}}=\frac{\partial I_{\mathrm{LUC}}(T)}{\partial s_{\mathrm{v}}}=\frac{\partial I_{\mathrm{LUC}}(T)}{\partial s_{\mathrm{vD}}}=-\frac{c c f D^{2} M_{\mathrm{R}} P A s c f L^{m_{\mathrm{i}}}{ }^{2}}{\left(s_{\mathrm{v}}+s_{\mathrm{vD}}\right)} .
$$

(x) Sensitivity coefficient for the color-correction factor $(c c f)$ :

$$
c_{c c f}=\frac{\partial I_{\mathrm{LUC}}(T)}{\partial c c f}=\frac{D^{2} M_{\mathrm{R}} P A s c f L^{m_{\mathrm{i}}}}{\left(s_{\mathrm{v}}+s_{\mathrm{vD}}\right)} .
$$

(xi) Sensitivity coefficient for the stray-light-correction factor $(s c f)$ :

$$
c_{s c f}=\frac{\partial I_{\mathrm{LUC}}(T)}{\partial s c f}=\frac{c c f D^{2} M_{\mathrm{R}} P A L^{m_{\mathrm{i}}}{ }^{\prime}}{\left(s_{\mathrm{v}}+s_{\mathrm{vD}}\right)}
$$

(xii) Sensitivity coefficient for the measurement repeatability $\left(M_{\mathrm{R}}\right)$ :

$$
c_{M_{\mathrm{R}}}=\frac{\partial I_{\mathrm{LUC}}(T)}{\partial M_{\mathrm{R}}}=\frac{c c f D^{2} P A s c f L^{m_{\mathrm{i}}}}{\left(s_{\mathrm{v}}+s_{\mathrm{vD}}\right)} .
$$

(xiii) Sensitivity coefficients for vertical $\left(L_{a \epsilon}\right)$ and horizontal $\left(L_{a \phi}\right)$ alignments of the lamp filament, angular alignment of the $\mathrm{RP}\left(\left(P_{a \theta}\right)\right.$ and non-linearity $\left(P_{\mathrm{N}}\right)$ of the RP):

$$
\begin{aligned}
c_{L_{a \epsilon}} & =c_{L_{a \phi}}=c_{P_{\theta}}=c_{P_{\mathrm{N}}}=\frac{\partial I_{\mathrm{LUC}}(T)}{\partial L_{a \epsilon}}=\frac{\partial I_{\mathrm{LUC}}(T)}{\partial L_{a \phi}}=\frac{\partial I_{\mathrm{LUC}}(T)}{\partial P_{\theta}}=\frac{\partial I_{\mathrm{LUC}}(T)}{\partial P_{\mathrm{N}}} \\
& =-\frac{c c f D^{2} M_{\mathrm{R}} P s c f L^{m_{\mathrm{i}}}}{\left(s_{\mathrm{v}}+s_{\mathrm{VD}}\right)} .
\end{aligned}
$$

\section{Appendix B: Determination of sensitivity coefficients for the luminous flux calibration}

The sensitivity coefficient for each the input quantity, given in Table II, was calculated by taking the partial derivative of the model function $f$ with respect to the input quantity using model Eq. (8). For the simplification, the following abbreviations may be accepted:

$$
\frac{\left(c_{\mathrm{ADVM}}+c_{\mathrm{ADVMD}}\right) U_{\mathrm{A}}}{J_{\mathrm{A}} R_{\mathrm{A}}\left(1+R_{\mathrm{D}}+\alpha_{\mathrm{RS}} \Delta T\right)}=L_{\mathrm{A}} .
$$
follows:

Thus, the sensitivity coefficient of each input quantity will be calculated as

(i) Sensitivity coefficients for the calibration factor $\left(c_{\mathrm{ADVM}}\right)$ and short-term drift 
$\left(c_{\mathrm{ADVMD}}\right)$ of the DVM:

$$
\begin{aligned}
& c_{c_{\mathrm{ADVM}}}+c_{c_{\mathrm{ADVMD}}}=\frac{\partial \Phi_{\mathrm{LUC}}}{\partial c_{\mathrm{ADVM}}}=\frac{\partial \Phi_{\mathrm{LUC}}}{\partial c_{\mathrm{ADVMD}}} \\
& =\frac{c c f m_{\mathrm{i}} M_{\mathrm{R}} P_{\mathrm{LUC}} P_{\mathrm{AWSL}} t_{\mathrm{LUC}} U_{\mathrm{A}} U_{\mathrm{LUC}}}{J_{\mathrm{A}} P_{\mathrm{WSL}} P_{\mathrm{ALUC}} t_{\mathrm{WSL}} U_{\mathrm{WSL}}} \times \frac{L_{\mathrm{A}}^{-1+m_{\mathrm{i}}} \Phi_{\mathrm{WSL}}\left(1-P_{\mathrm{N}}\right)}{R_{\mathrm{A}}\left(1+R_{\mathrm{D}}+\alpha_{\mathrm{RS}} \Delta T\right)} .
\end{aligned}
$$

(ii) Sensitivity coefficient for the voltage $\operatorname{drop}\left(U_{\mathrm{A}}\right)$ :

$$
\begin{aligned}
c_{U_{\mathrm{A}}} & =\frac{\partial \Phi_{\mathrm{LUC}}}{\partial U_{\mathrm{A}}}=\frac{c c f\left(c_{\mathrm{ADVM}}+c_{\mathrm{ADVMD}}\right) m_{\mathrm{i}} M_{\mathrm{R}} P_{\mathrm{LUC}} P_{\mathrm{AWSL}} t_{\mathrm{LUC}} U_{\mathrm{LUC}}}{J_{\mathrm{A}} P_{\mathrm{WSL}} P_{\mathrm{ALUC}} t_{\mathrm{WSL}} U_{\mathrm{WSL}}} \\
& \times \frac{L_{\mathrm{A}}^{-1+m_{\mathrm{i}}} \Phi_{\mathrm{WSL}}\left(1-P_{\mathrm{N}}\right)}{R_{\mathrm{A}}\left(1+R_{\mathrm{D}}+\alpha_{\mathrm{RS}} \Delta T\right)} .
\end{aligned}
$$

(iii) Sensitivity coefficient for the operating current of $J_{\mathrm{A}}$

$$
\begin{aligned}
c_{J_{\mathrm{A}}}= & \frac{\partial \Phi_{\mathrm{LUC}}}{\partial J_{\mathrm{A}}}=-\frac{c c f\left(c_{\mathrm{ADVM}}+c_{\mathrm{ADVMD}}\right) m_{\mathrm{i}} M_{\mathrm{R}} P_{\mathrm{LUC}} P_{\mathrm{AWSL}} t_{\mathrm{LUC}} U_{\mathrm{A}} U_{\mathrm{LUC}}}{J_{\mathrm{A}}^{2} P_{\mathrm{WSL}} P_{\mathrm{ALUC}} t_{\mathrm{WSL}} U_{\mathrm{WSL}}} \\
& \times \frac{L_{\mathrm{A}}^{-1+m_{\mathrm{i}}} \Phi_{\mathrm{WSL}}\left(1-P_{\mathrm{N}}\right)}{R_{\mathrm{A}}\left(1+R_{\mathrm{D}}+\alpha_{\mathrm{RS}} \Delta T\right)} .
\end{aligned}
$$

(iv) Sensitivity coefficient for the resistance value $\left(R_{\mathrm{A}}\right)$ :

$$
\begin{aligned}
c_{R_{\mathrm{A}}} & =\frac{\partial \Phi_{\mathrm{LUC}}}{\partial R_{\mathrm{A}}}=-\frac{c c f\left(c_{\mathrm{ADVM}}+c_{\mathrm{ADVMD}}\right) m_{\mathrm{i}} M_{\mathrm{R}} P_{\mathrm{LUC}} P_{\mathrm{AWSL}} t_{\mathrm{LUC}} U_{\mathrm{A}} U_{\mathrm{LUC}}}{J_{\mathrm{A}} P_{\mathrm{WSL}} P_{\mathrm{ALUC}} t_{\mathrm{WSL}} U_{\mathrm{WSL}}} \\
& \times \frac{L_{\mathrm{A}}^{-1+m_{\mathrm{i}}} \Phi_{\mathrm{WSL}}\left(1-P_{\mathrm{N}}\right)}{R_{\mathrm{A}}\left(1+R_{\mathrm{D}}+\alpha_{\mathrm{RS}} \Delta T\right)} .
\end{aligned}
$$

(v) Sensitivity coefficients for the short-term drift $\left(R_{\mathrm{D}}\right)$ and the temperature coefficient $\left(\alpha_{\mathrm{RS}} \Delta T\right)$ :

$$
\begin{aligned}
c_{R_{\mathrm{D}}} & =c_{\alpha_{\mathrm{RS}} \Delta T}=\frac{\partial \Phi_{\mathrm{LUC}}}{\partial R_{\mathrm{D}}}=\frac{\partial \Phi_{\mathrm{LUC}}}{\partial \alpha_{\mathrm{RS}} \Delta T} \\
& =-\frac{c c f\left(c_{\mathrm{ADVM}}+c_{\mathrm{ADVMD}}\right) m_{\mathrm{i}} M_{\mathrm{R}} P_{\mathrm{LUC}} P_{\mathrm{AWSL}}}{J_{\mathrm{A}} P_{\mathrm{WSL}} P_{\mathrm{ALUC}} t_{\mathrm{WSL}} U_{\mathrm{WSL}}} \\
& \times \frac{t_{\mathrm{LUC}} U_{\mathrm{A}} U_{\mathrm{LUC}} L_{\mathrm{A}}^{-1+m_{\mathrm{i}}} \Phi_{\mathrm{WSL}}\left(1-P_{\mathrm{N}}\right)}{R_{\mathrm{A}}\left(1+R_{\mathrm{D}}+\alpha_{\mathrm{RS}} \Delta T\right)^{2}} .
\end{aligned}
$$

(vi) Sensitivity coefficients for the exponent $\left(m_{\mathrm{i}}\right)$ :

$$
\begin{aligned}
c_{m_{\mathrm{i}}} & =\frac{\partial \Phi_{\mathrm{LUC}}}{\partial m_{\mathrm{i}}} \\
& =\frac{c c f \log \left(L_{\mathrm{A}}\right) M_{\mathrm{R}} P_{\mathrm{LUC}} P_{\mathrm{AWSL}} t_{\mathrm{LUC}} U_{\mathrm{LUC}} L_{\mathrm{A}}^{m_{\mathrm{i}}} \Phi_{\mathrm{WSL}}\left(1-P_{\mathrm{N}}\right)}{P_{\mathrm{WSL}} P_{\mathrm{ALUC}} t_{\mathrm{WSL}} U_{\mathrm{WSL}}} .
\end{aligned}
$$

(vii) Sensitivity coefficients for the voltage drop $\left(U_{\mathrm{LUC}}\right)$ :

$$
c_{U_{\mathrm{LUC}}}=\frac{\partial \Phi_{\mathrm{LUC}}}{\partial U_{\mathrm{LUC}}}=\frac{c c f M_{\mathrm{R}} P_{\mathrm{LUC}} P_{\mathrm{AWSL}} t_{\mathrm{LUC}} L_{\mathrm{A}}^{m_{\mathrm{i}}} \Phi_{\mathrm{WSL}}\left(1-P_{\mathrm{N}}\right)}{P_{\mathrm{WSL}} P_{\mathrm{ALUC}} t_{\mathrm{WSL}} U_{\mathrm{WSL}}} .
$$

(viii) Sensitivity coefficients for the voltage drop $\left(U_{\mathrm{WSL}}\right)$ :

$$
c_{U_{\mathrm{WSL}}}=\frac{\partial \Phi_{\mathrm{LUC}}}{\partial U_{\mathrm{WSL}}}
$$




$$
=-\frac{c c f M_{\mathrm{R}} P_{\mathrm{LUC}} P_{\mathrm{AWSL}} t_{\mathrm{LUC}} U_{\mathrm{LUC}} L_{\mathrm{A}}^{m_{\mathrm{i}}} \Phi_{\mathrm{WSL}}\left(1-P_{\mathrm{N}}\right)}{P_{\mathrm{WSL}} P_{\mathrm{ALUC}} t_{\mathrm{WSL}} U_{\mathrm{WSL}}^{2}} .
$$

(ix) Sensitivity coefficients for the luminous flux of the WSL ( $\left.\Phi_{\mathrm{WSL}}\right)$ :

$$
c_{\Phi_{\mathrm{WSL}}}=\frac{\partial \Phi_{\mathrm{LUC}}}{\partial \Phi_{\mathrm{WSL}}}=\frac{c c f M_{\mathrm{R}} P_{\mathrm{LUC}} P_{\mathrm{AWSL}} t_{\mathrm{LUC}} U_{\mathrm{LUC}} L_{\mathrm{A}}^{m_{\mathrm{i}}}\left(1-P_{\mathrm{N}}\right)}{P_{\mathrm{WSL}} P_{\mathrm{ALUC}} t_{\mathrm{WSL}} U_{\mathrm{WSL}}} .
$$

(x) Sensitivity coefficient for the photocurrent $\left(P_{\mathrm{LUC}}\right)$ :

$$
c_{P_{\mathrm{LUC}}}=\frac{\partial \Phi_{\mathrm{LUC}}}{\partial P_{\mathrm{LUC}}}=-\frac{c c f M_{\mathrm{R}} P_{\mathrm{AWSL}} t_{\mathrm{LUC}} U_{\mathrm{LUC}} L_{\mathrm{A}}^{m_{\mathrm{i}}}\left(1-P_{\mathrm{N}}\right) \Phi_{\mathrm{WSL}}}{P_{\mathrm{WSL}} P_{\mathrm{ALUC}} t_{\mathrm{WSL}} U_{\mathrm{WSL}}} .
$$

(xi) Sensitivity coefficient for the photocurrent $\left(P_{\mathrm{WSL}}\right)$ :

$$
\begin{aligned}
c_{P_{\mathrm{WSL}}} & =\frac{\partial \Phi_{\mathrm{LUC}}}{\partial P_{\mathrm{WSL}}} \\
= & -\frac{c c f M_{\mathrm{R}} P_{\mathrm{LUC}} P_{\mathrm{AWSL}} t_{\mathrm{LUC}} U_{\mathrm{LUC}} L_{\mathrm{A}}^{m_{\mathrm{i}}}\left(1-P_{\mathrm{N}}\right) \Phi_{\mathrm{WSL}}}{P_{\mathrm{WSL}}^{2} P_{\mathrm{ALUC}} t_{\mathrm{WSL}} U_{\mathrm{WSL}}} .
\end{aligned}
$$

(xii) Sensitivity coefficient for the photocurrent $\left(P_{\mathrm{AWSL}}\right)$ :

$$
c_{P_{\mathrm{AWSL}}}=\frac{\partial \Phi_{\mathrm{LUC}}}{\partial P_{\mathrm{AWSL}}}=-\frac{c c f M_{\mathrm{R}} P_{\mathrm{LUC}} t_{\mathrm{LUC}} U_{\mathrm{LUC}} L_{\mathrm{A}}^{m_{\mathrm{i}}}\left(1-P_{\mathrm{N}}\right) \Phi_{\mathrm{WSL}}}{P_{\mathrm{WSL}} P_{\mathrm{ALUC}} t_{\mathrm{WSL}} U_{\mathrm{WSL}}} .
$$

(xiii) Sensitivity coefficient for the photocurrent $\left(P_{\mathrm{ALUC}}\right)$ :

$$
\begin{aligned}
c_{P_{\mathrm{ALUC}}} & =\frac{\partial \Phi_{\mathrm{LUC}}}{\partial P_{\mathrm{ALUC}}} \\
= & -\frac{c c f M_{\mathrm{R}} P_{\mathrm{AWSL}} P_{\mathrm{LUC}} t_{\mathrm{LUC}} U_{\mathrm{LUC}} L_{\mathrm{A}}^{m_{\mathrm{i}}}\left(1-P_{\mathrm{N}}\right) \Phi_{\mathrm{WSL}}}{P_{\mathrm{WSL}} P_{\mathrm{ALUC}}^{2} t_{\mathrm{WSL}} U_{\mathrm{WSL}}} .
\end{aligned}
$$

(xiv) Sensitivity coefficient for the temperature $\left(t_{\mathrm{LUC}}\right)$ :

$$
c_{t_{\mathrm{LUC}}}=\frac{\partial \Phi_{\mathrm{LUC}}}{\partial t_{\mathrm{LUC}}}=\frac{c c f M_{\mathrm{R}} P_{\mathrm{AWSL}} P_{\mathrm{LUC}} U_{\mathrm{LUC}} L_{\mathrm{A}}^{m_{\mathrm{i}}}\left(1-P_{\mathrm{N}}\right) \Phi_{\mathrm{WSL}}}{P_{\mathrm{WSL}} P_{\mathrm{ALUC}} t_{\mathrm{WSL}} U_{\mathrm{WSL}}} .
$$

(xv) Sensitivity coefficient for the temperature $\left(t_{\mathrm{WSL}}\right)$ :

$$
\begin{aligned}
c_{t_{\mathrm{WSL}}} & =\frac{\partial \Phi_{\mathrm{LUC}}}{\partial t_{\mathrm{WSL}}} \\
& =-\frac{c c f M_{\mathrm{R}} P_{\mathrm{AWSL}} P_{\mathrm{LUC}} t_{\mathrm{LUC}} U_{\mathrm{LUC}} L_{\mathrm{A}}^{m_{\mathrm{i}}}\left(1-P_{\mathrm{N}}\right) \Phi_{\mathrm{WSL}}}{P_{\mathrm{WSL}} P_{\mathrm{ALUC}} t_{\mathrm{WSL}}^{2} U_{\mathrm{WSL}}} .
\end{aligned}
$$

(xvi) Sensitivity coefficient for the color-correction factor $(c c f)$ :

$$
c_{c c f}=\frac{\partial \Phi_{\mathrm{LUC}}}{\partial c c f}=\frac{M_{\mathrm{R}} P_{\mathrm{AWSL}} P_{\mathrm{LUC}} t_{\mathrm{LUC}} U_{\mathrm{LUC}} L_{\mathrm{A}}^{m_{\mathrm{i}}}\left(1-P_{\mathrm{N}}\right) \Phi_{\mathrm{WSL}}}{P_{\mathrm{WSL}} P_{\mathrm{ALUC}} t_{\mathrm{WSL}} U_{\mathrm{WSL}}} .
$$

(xvii) Sensitivity coefficient for the measurement repeatability $\left(M_{\mathrm{R}}\right)$ :

$$
c_{M_{\mathrm{R}}}=\frac{\partial \Phi_{\mathrm{LUC}}}{\partial M_{\mathrm{R}}}=\frac{c c f P_{\mathrm{AWSL}} P_{\mathrm{LUC}} t_{\mathrm{LUC}} U_{\mathrm{LUC}} L_{\mathrm{A}}^{m_{\mathrm{i}}}\left(1-P_{\mathrm{N}}\right) \Phi_{\mathrm{WSL}}}{P_{\mathrm{WSL}} P_{\mathrm{ALUC}} t_{\mathrm{WSL}} U_{\mathrm{WSL}}} .
$$

(xviii) Sensitivity coefficients for non-linearity $\left(P_{\mathrm{N}}\right)$ :

$$
c_{P_{\mathrm{N}}}=\frac{\partial \Phi_{\mathrm{LUC}}}{\partial P_{\mathrm{N}}}=-\frac{c c f M_{\mathrm{R}} P_{\mathrm{AWSL}} P_{\mathrm{LUC}} t_{\mathrm{LUC}} U_{\mathrm{LUC}} L_{\mathrm{A}}^{m_{\mathrm{i}}} \Phi_{\mathrm{WSL}}}{P_{\mathrm{WSL}} P_{\mathrm{ALUC}} t_{\mathrm{WSL}} U_{\mathrm{WSL}}} .
$$




\section{Appendix C: Determination of sensitivity coefficients for the luminance calibration}

The sensitivity coefficient for each input quantity, given in Table III, was calculated by taking the partial derivative of the model function $f$ with respect to the input quantity using model Eq. (10). For the simplification, the following abbreviations may be accepted:

$$
\begin{aligned}
& \left(d+d_{\mathrm{p}}+\alpha_{\mathrm{RS}} \Delta T\right)=D, \quad\left(P_{\mathrm{c}}+c_{\mathrm{PCM}}+c_{\mathrm{PCMD}}\right)=P, \\
& \left(1-L S_{a \epsilon}-P_{a \theta}-P_{\mathrm{N}}\right)=E .
\end{aligned}
$$

Thus, the sensitivity coefficient of each input quantity will be calculated as follows:

(i) Sensitivity coefficients for the distance $(d)$, offset distance $\left(d_{\mathrm{p}}\right)$ and thermal expansion coefficient $\left(\alpha_{\mathrm{RS}} \Delta T\right)$ :

$$
\begin{aligned}
c_{d}= & c_{d_{\mathrm{p}}}=c_{\alpha_{\mathrm{RS}} \Delta T}=\frac{\partial L_{\mathrm{LSUC}}}{\partial d}=\frac{\partial L_{\mathrm{LSUC}}}{\partial d_{\mathrm{p}}}=\frac{\partial L_{\mathrm{LSUC}}}{\partial \alpha_{\mathrm{RS}} \Delta T} \\
& =\frac{2 c c f s c f D M_{\mathrm{R}} P E}{A\left(s_{\mathrm{v}}+s_{\mathrm{VD}}\right)} .
\end{aligned}
$$

(ii) Sensitivity coefficient for the aperture area $(A)$ :

$$
c_{A}=\frac{\partial L_{\mathrm{LSUC}}}{\partial A}=-\frac{c c f s c f D^{2} M_{\mathrm{R}} P E}{A^{2}\left(s_{\mathrm{v}}+s_{\mathrm{vD}}\right)} .
$$

(iii) Sensitivity coefficients for the photocurrent $\left(P_{\mathrm{c}}\right)$, calibration factor $\left(c_{\mathrm{PCM}}\right)$ and short-term drift $\left(c_{\mathrm{PCMD}}\right)$ :

$$
\begin{aligned}
c_{P_{\mathrm{c}}} & =c_{c_{\mathrm{PCM}}}=c_{c_{\mathrm{PCMD}}}=\frac{\partial L_{\mathrm{LSUC}}}{\partial P_{\mathrm{c}}}=\frac{\partial L_{\mathrm{LSUC}}}{\partial c_{\mathrm{PCM}}}=\frac{\partial L_{\mathrm{LSUC}}}{\partial c_{\mathrm{PCMD}}} \\
& =\frac{c c f s c f D^{2} M_{\mathrm{R}} E}{A\left(s_{\mathrm{v}}+s_{\mathrm{vD}}\right)} .
\end{aligned}
$$

(iv) Sensitivity coefficients for the illuminance responsivity $\left(s_{\mathrm{v}}\right)$ and short-term $\operatorname{drift}\left(s_{\mathrm{vD}}\right)$ :

$$
c_{s_{\mathrm{v}}}=c_{s_{\mathrm{vD}}}=\frac{\partial L_{\mathrm{LSUC}}}{\partial s_{\mathrm{v}}}=\frac{\partial L_{\mathrm{LSUC}}}{\partial s_{\mathrm{vD}}}=-\frac{c c f s c f D^{2} M_{\mathrm{R}} P E}{A\left(s_{\mathrm{v}}+s_{\mathrm{vD}}\right)^{2}} .
$$

(v) Sensitivity coefficient for the color-correction factor $(c c f)$ :

$$
c_{c c f}=\frac{\partial L_{\mathrm{LSUC}}}{\partial c c f}=\frac{s c f D^{2} M_{\mathrm{R}} P E}{A\left(s_{\mathrm{v}}+s_{\mathrm{vD}}\right)} .
$$

(vi) Sensitivity coefficient for the stray-light-correction factor $(s c f)$ :

$$
c_{s c f}=\frac{\partial L_{\mathrm{LSUC}}}{\partial s c f}=\frac{c c f D^{2} M_{\mathrm{R}} P E}{A\left(s_{\mathrm{v}}+s_{\mathrm{vD}}\right)} .
$$

(vii) Sensitivity coefficient for the measurement repeatability $\left(M_{\mathrm{R}}\right)$ :

$$
c_{M_{\mathrm{R}}}=\frac{\partial L_{\mathrm{LSUC}}}{\partial M_{\mathrm{R}}}=\frac{c c f s c f D^{2} P E}{A\left(s_{\mathrm{v}}+s_{\mathrm{vD}}\right)} .
$$

(viii) Sensitivity coefficients for the perpendicularity alignment of the LSUC 
$\left(L S_{a \epsilon}\right)$, angular alignment of the photometer $\left(P_{a \theta}\right)$ and the non-linearity $\left(P_{\mathrm{N}}\right)$ :

$$
c_{L S_{\mathrm{a} \epsilon}}=c_{P_{\mathrm{a} \theta}}=c_{P_{\mathrm{N}}}=\frac{\partial L_{\mathrm{LSUC}}}{\partial L S_{\mathrm{a} \epsilon}}=\frac{\partial L_{\mathrm{LSUC}}}{\partial P_{\mathrm{N}}}=\frac{c c f s c f D^{2} M_{\mathrm{R}} P}{A\left(s_{\mathrm{v}}+s_{\mathrm{vD}}\right)} .
$$

\section{References}

[1] International Organization for Standardization, Guide to the Expression of Uncertainty in Measurement, 2nd ed., Geneva 1995.

[2] European co-operation for Accreditation, Expression of the Uncertainty of Measurement in Calibration, EA-4/02, 1999.

[3] K.D. Sommer, B.R.L. Siebert, Metrologia 43, 200 (2006).

[4] R. Kessel, R. Kacker, M. Berglund, Metrologia 43, 189 (2006).

[5] F. Samedov, O. Bazkir, Eur. Phys. J. Appl. Phys. 30, 205 (2005).

[6] F. Samedov, M. Durak, O. Bazkir, Opt. Lasers Eng. 43, 1252 (2005).

[7] J.H. Walker, A. Thompson, J. Res. Natl. Inst. Stand. Technol. 99, 255 (1994).

[8] M.S. Rea, Lighting Handbook: Reference $\&$ Application, 8th ed., Illuminating Engineering Society of North America, New York 1993.

[9] A. Pons, J. Campos, A. Corróns, F. Samedov, Metrologia, Tech. Suppl. 42, 02002 (2005).

[10] F. Sametoglu, Opt. Eng. 46, 093607-1 (2007).

[11] F. Sametoglu, Opt. Rev. 13, 326 (2006).

[12] F. Samedov, M. Durak, Opt. Appl. 34, 265 (2004).

[13] F. Sametoglu, Opt. Lasers Eng. 45, 36 (2007). 